aspects of this recent work have been reviewed previously, there has hitherto been no reasonably comprehensive account of both root and shoot apical meristems. This need has now been met by the new book written by Dr. Clowes.

Althcugh Dr. Clowes' own research work has been mainly on root apices, shoot meristems receive adequate consideration; in fact eleven of the seventeen chapters deal mainly with shoot apices. Recent work involving new techniques is discussed in some detail, but the anatomical side is not neglected. Chapters on planes of division in shoot and root apices include discussions of the tunica-corpus hypothesis of the shoot apex and of the similar, but less well-known, Körper-Kappe hypothesis of the root meristem. A complete chapter is devoted to the bearing of the evidence from chimeras on controversies relating to the shoot apex. The sections of the book dealing with the rates of cell division in both root and shoot apices are particularly informative, and it would seem that the newor techniques, including autoradiography, have demonstrated the existence of a 'quiescent' centre in the root apices investigated. It has also been shown that, in opposition to the views of the French school, there is no 'méristème d'attente' in the shoot apex.

The book is not restricted to a consideration of apical meristems in the narrow sense, but covers in addition such topics as the development of leaves, the determination of sites of leaves, the differentiation and origin of procambium, latitudinal growth in apices and the formation of floral apices. There is also a dotailed consideration of differentiation in the root apex.

The text figures of apices are not very numerous, but are supplemented by 32 photographs including some striking autoradiographs of shoot and root apices. The clear readable style is an admirable feature of the book, which is a useful addition to the new series of botanical monographs. A. AxlsopP

\section{ELECTROLYTES AND PLANT CELLS}

Electrolytes and Plant Cells

By Prof. G. E. Briggs, Dr. A. B. Hope, and Prof. R. N. Robortson. (Botanical Monographs, Vol. 1.) Pp. $x+217$. (Oxford: Blackwell Scientific Publications; Springfield, Ill.: Charles C. Thomas, 1961.) 408. net.

HE stated purpose of this new series of Botanieal

Monographs is to inform the advanced student, assist the lecturer and be a point of departiure for the specialist. The first volume admirably fulfils these aims.

Forty pages at the beginning are dovoted to an account of the physical properties of electrolytes in solution. The principles of ionic exchange receive little attention, but diffusion and Donnan equilibria are dealt with handeomely. Plant cells merit no more than passing mention until Chapter 4, which contains an elemontary account of the gross structure of three types. Chapter 5 deals with fine structure as revealed, albeit still imperfoctly, by electronmicroscopic investigations. One is left wondering how sonn it will be possible to apply the physico. chemical principles outlined earlier to the immensely complex and ever-changing cytoplasm. At presont only the inert cellulose wall seems amenable to such an approach.
The concept of 'free space' receives detailed consideration in Part 2. For the benefit of the uninitiated, free space may be defined as that part of a cell or tissue into and through which solutes move readily by physical processes. The authors have at various times separately suggested that cytoplasm forms part of the free space. They now conclud 9 that it can be adequately accommodated in water-fillod spaces in and around the cell wall. This is a return to the classical view-never relinquished by more conservative plant physiologists, who are unable to accept the idea of cytoplasm being freely accessible to the vicissitudes of the environment. The possibility that a small but more interesting fraction of the free space may be associated with the cytoplasm is still not excluded, but adequate evidence is lacking.

Part 3 is concerned with the active absorption of salts and its connexion with metabolism. The principles of an ion-carrier mechanism are set out, and a general scheme linking anion transport to electron flow is outlined. Cation movement is said to occur passively along an electro-chemical potential gradient established by anion movements. No explanation is offored for the active extrusion of sodium ions which occurs in some algae and in yoast. It is surprising that Conway's 'redox pump' is not mentioned in this context since it seems to differ fundamentally from the mechanism proposed only in that it is designed to transport cations rather than anions. Presumably in the authors' minds yeast is not looked on as a respectable plant cell, but surely it is unwise to confine one's at tention narrowly in discussing such a fundamental biological process as ion-transport.

In a short final section, some aspects of salt absorp. tion and transport in organs and intact vascular plants are reviowed. It is evidont that adequate understanding of these processes which involve yet another level of complexity must await further knowledge of ion movements at the cellular and sub-cellular levels.

JAMES F. SUTCLIFFF:

\section{ORCHIDS OF TRINIDAD AND TOBAGO}

Native Orchids of Trinidad and Tobago

By Dr. Richard Evans Schultes. (International Series of Monographs on Pure and Applied Biology. Division: Botany, Vol. 3.) Pp. $x+275+21$ plates. (Londion and New York: Pergamon Press, 1960.) 100s. net.

THE third volume in the Pergamon Press's

Botanical Division of its new series of Biological Monographs endeavours to maintain the standards set by the two previous volumes of Dr. Turrill and Dr. Bor on general botany and Indian grasses respectively.

Constituting the second largest plant family in Trinidad and Tobago the 180 species of Orchidaceae occurring there merit an account. The continued use of Trinidad as an exporting centre for American plants, combined with the fact that so many of its orchids are at the same time beautiful, horticulturally amenable and scientifically interesting, doubly merits an account of the colony's orchids. 'This was realized long ago, and Grisebach (1864), Cogniaux (1910), Broadway (1918-32) and Wilson (1925) all published accounts of the species of the area, but it has been 